\title{
XXXVII. History of astronomy for the year 1803. Read at the College de France
}

\author{
Jerome de Lalande
}

To cite this article: Jerome de Lalande (1804) XXXVII. History of astronomy for the year 1803. Read at the College de France, Philosophical Magazine Series 1, 18:71, 209-221, DOI: $10.1080 / 14786440408676480$

To link to this article: http://dx.doi.org/10.1080/14786440408676480

曲 Published online: 18 May 2009.

Submit your article to this journal $\lceil\pi$

Џll Article views: 2

Q View related articles $\square$ 
air. His dyspepsia had existed two years :- "From the first day inhaling the vital air, found every thing stay on my stomach: before I vomited every thing up; before, animal food took such an effect upon me, that I was obliged to leave the room where any joint was : now I eat every thing with an appetite, and, after returning from inhaling the vital air, am disposed to devour even the victuals in the street."-This patient has left off the vital air, as considering himself cured.

I have the honour to rel, , \&c.

Robert N Thonnton

XXXVII. History of Astronomy for the Year 1803. Read at the College de France by Jerome de Lalande*.

$\mathrm{T}$ T

Trrs year will not appear so remarkable as the two preceding ones, in which new planets and comets were discovered; but it presents a series of important labours undertaken for the improvement of the science, either terminated or begun.

M. Piazzi has published at Palermo a very valuable work; a catalogue of nearly 7000 stars, each observed several times with excellent instruments calculated and reduced to the year 1800 . It was at the College de France that the author, fifteen years ago, made preparations for this immense labour. We have received the catalogue of 500 stars by M. Cagnoli, with their right ascensions and declinations, which are very correct : on this work he has been employed twenty years.

Lalande my nephew, with his new aids and an immense number of his own observations, has entirely reconstructed the catalogue of 600 new stars, which for many years he has inserted in the Connoissance des Temps, and which serves as a foundation for the calculations of the greater part of our astronomers.

As the stars are the foundation of all our astronomical determinations, Dr. Maskelyne has carefully revised the thirty-four stars which he announced as having the utmost degree of precision, and which we have ali emplnyed, as being entitled to full confidence : he found in them an error of 4 .

The interruption of our correspondence with England during the war has induced me to undertake a very considerable labour.

From the Magaxin Encyrlypedique, no. 15, Nivose, an 12.

Voc. XVIII. No. 71 . 
I have calculated some hundreds of the sun's altitudes observed in England and France, for several years back, before and after the equinox; and have deduced from them the sun's right ascension, and conserquently that of the stars which had been compared with him. I have found that it is necessary to add $5^{\prime \prime}$ to the positions of the stars which Dr. Maskelyne gave us as being certain to a second, and which all astronomers employed with the greatest security : but perceiving that observations made at the distance of $40^{\circ}$ from the zcnith and at $60^{\circ}$ gave right asccinsions which differed sometimes $15^{\prime \prime}$, I concluded that there were crrors of division of $5^{\prime \prime}$ in the interval of 20 degrees : it will therefore be necessary to recur to the whole circle, to verify the mural quadrants employed at Paris and at Greenwich.

$I$ was at first surprised to find errors of $10^{\prime \prime}$ and then of $20^{\prime \prime}$ in the right ascensions; but $I$ thought them of less consequence when I saw that from 42 to 45 degrees they were $10^{\prime \prime}$, and that from 54 to 56 they amounted to $20^{\prime \prime}$. The medium, thercfore, between results very different is found to be the same, because the altitudes correspond at the two seasons, and the sum of the small errors compensates for that of the great.

To remcdy this inconrenience in the divisions of the mural quadiant, M. Delambre this year observed the sun for two months, partly beforc and partly after the autumnal equinox, with a multiplying circle, and by 300 observations he had places of the sun independent of the stars. But a second in the refraction, or in the height of the pole, may oceasion all the uncertainty : it will, however, be removed at the next equinox.

Picard and La Hire in the seventeenth century made the first correct observations for accomplishing this end, and the French in the present century will have made the last tó attain it completely.

Herschel asserts that the stars called Castor $\gamma$ of the Lion, and several other double stars very near to each other, turn round in periods of some centuries. M. Triesnecker is not of opinion with $\mathbf{M}$. Flauguergues, that in the double star? of the Great Bear the two parts have changed: there are 14 distance between the two stars of which it is composed.

M. Vidal has observed at Mirepois zones of the circumpolar stars which were wanting.

M. Delambre at the summer solstice made an observation of the obliquity of the ediptic with a multiplying circle. The mean of four years observations, and of two years made 
by my nephew Lalande, gave as the mean for $180023^{\circ} 28^{\prime}$ : this is the result of more than 1500 observations; but it supposes the height of the pole to be $48^{\circ} 50^{\prime} 13^{\prime \prime}$ instead of $14^{\prime \prime}$, and the latter supposes the refraction of Bradley increased by $1^{\prime \prime}$. By these means he makes the winter to agree with the summer solstice, between which there was a difference of 7 or $8^{\prime \prime}$. The bad weather did not permit him to observe the winter solstice with the circle which I caused to be constructed by Lenoir for the observatory of Palermo. The astronomers Bradley, Lacaille, and Mayer, found for $175023^{\circ} 28^{\prime} 18^{\circ} 5^{\prime \prime}$; the secular decrease, therefore, would be $42^{\prime \prime}$ per century; and I prefer this result to that of the equation of the sun produced by Venus, which would give $50^{\prime \prime}$.

Dr. Maskelyne found with a mural quadrant at Greenwich $23^{\circ} 27^{\prime} 57^{\prime \prime}$; but the English have not yet adopted our repeating circles, with which one may be certain to a second, and with which no errors in the divisions are to be apprehended.

Piazzi, at Palermo, found $23^{\circ} 27^{\prime} 56^{\circ} 6^{\prime \prime}$ with an excellent circle by Ramsden, but not a repeating circle.

The Academy of Berlin has still proposed, for 1806 , the determination of the obliquity of the ecliptic, both by theory and observation. The details are contained in the Moniteur of November the first. But little remains to be done in that respect.

The refraction still contains a doubeful element; it is the correction required by the density of the atmosphere.

M. Gay has presented to the Institute an interesting me moir on this subject, and there is one in the Transactions of the Society of Manchester: an extract of it has been inserted in the Billiothèque Britannique published at Geneva.

The measure of a degree of the carth in Lapland, which M. Melanderhielm has procured for us, and the calculations it required, were transmitted to us in the month of April by Messrs. Svauberg, Overbom, Holmquist, and Palander : they have found the degree to be 57197 toises. That found by Maupertuis, Clairaut, Camus, Lemonnier, Outhier, and Celsius, in 1736, was 57405 , which is greater by 208 toises. This enormons difference was suspected. The degree of Lapland was at variance with all theory and with eviry other measurement : it gave to the earth too great a flattening; whereas the new degree gives $\frac{1}{3} 5$, which is not much different from the $\frac{1}{3+}$ giren by the new meridian of France, 
compared with the degree measured in Peru. It is, how ever, so difficult to admit an error of such magnitude, that we have requested information from Sweden on this subject.

M. Mechain set out on the 26th of April 1803 for Spain, to continue the meridian of France to the 39 th degree of latitude, that is to say, as far as the Balearian islands. He was accompanied by Mechain junior, Dezauche junior, and they were joined by M. Chaix, an able Spanish astronomer.

$I$ gave him an excellent circle of 19 inches radius, made by Lenoir; a telescope of a large aperture was added to it : there are twelve large reverberators, and he will be able to continue his triangles to Majorca and Ivica, though at the distance of 93000 toises from the coast of Catalonia, in the months of January, February, and March, which are those most favourable for such observations. In the mean time he has formed six subsidiary triangles between Barcelona and Tortosa, as detailed in the Moniteur of November 15. But in the midst of storms and tempests, surrounded by thunder, and sleeping under a tent upon straw, he has been obliged, for the purpose of completing his operations, to cause wooden huts to be constructed on summits the climate of which is dreadful. On the 27 th of October he was on the highest peaks of Montserrat for his last triangle. On the $23 \mathrm{~d}$ of November the whole were finished; bat the brig destined to carry him to the Balcarian islands, having lost twenty men by the yellow fever which broke out at Malaga, was obliged to perform quarantine, and Mechain could not proceed thither, though the court of Spain had given the necessary orders. At length on the sth of Jamuary he set out for Ivica, where, he will commence his operations. It seems to be dotermined that the war shall not prevent this uscful labour. By these means we shall have an exact measurement of 19 degrees, the mean of which will be the 45 th degree, the one we are most interested to know, to verify still better our universal measure and the magnirude of the earth.

C. Chaptal, our learned minister, to whom all the arts and sciences are under daily obligations, and by whom the College de France has been revived, wished also to dispense to astronomy the favours of an enlightened government of which he is the organ.

The observatory has received some new acquisitions. On the 17 th of August a meridian telescope eight feet long and of four inches aperture, and an axis of 46 inches, made at London by the celebrated Ramsden, wa erected, and on 
the 6th of September M. Bouvard observed the moon: he observed the equinox; and these operations will not be interrupted.

The minister has purchased a dividing machine for 12,000 francs, made by Samuel Rehe: it is 43 inches, and was bought by M. Andreossi after the death of that artist. It has the same form as that of Ramsden, the description of which I translated : it will probably be of use to our artists.

The large telescope of Caroche, which is 22 feet, and equal to that of Herschel of the same length, has hitherto been useless, because it wanted a stand to support it, and a terrace to be placed on. M. Tremel, an able mechanist who made the stand, dicd on the 13th of February, before he could finish it. Caroché had a terrible fall in attempting to use it; so that, notwithstanding the great expense we have been at, our enjoyment is still retarder.

M. de Narcy has made prisms of rock crystal placed over each other in such a manner, that the diameters of the sun and moon can be measured by the double refraction of Rochon : father Boscovich made use of it to measure small angles.

M. Lenoir has made a circle of 20 inches for M. Piazzi of Palermo, who proposes to measure a degree: he has. added to it a powerful telescope.

Government, by a decree of Vendemiaire 1st, determined that the standards of the metre and of the kilogramme, and of all the rules whieh have served for the different measures of the earth by the French astronomers, shall be deposited at the national observatory, under the inspection of the. Baard of Longitude.

The minister Chaptal has given a gratuity to M. Flauguergues, whose zeal for astronomy is still maintained at Viviers in an exemplary manner.

The minister, at my solicitation, caused also to be purchased, and deposited at the observatory, in the month of August, the observations of $M$. Lemonnier, which I have not had an opportunity of seeing. They consist of fourteen large volumes: the observations, which terminate at the 30th of October 1791 , have been printed up to the 6 th of June 1745 : but it is only since the 8th of April 1755 that they were made with the mural of $7 \frac{1}{2}$ feet. As those of Bradley are printed only for 1750-1755, and as those of Dr. Maskelyne do not begin till the month of May 1765, there is a gap of nearly ten years; to supply which we have recourse to the observations of $M$. Lemonnier, though not 


\section{History of Astronomy for the Year 1803.}

so correct as those of Greenwich. But Lemonnier observed more stars. I propose to unite to this deposit the observations of Picard, Louville, Lacaille, Bonguer, Bailly, and d'Agelet, which are in my hands.

M. Bouvard has made at the Luxembourg, or palace of the senate, an excellent meridian of mean time, which it is much to be wished the public would use, as is done in England and even at Geneva, and as those do who have good timc-keepers by Berthoud and Breguet. Our small annuary gives the difference for each day, which amounts at most to a quarter of an hour. On the 27 th of September I renewed, at the Institute, the proposal of setting the example by adopting mean time, which alone is regular, and can form a real measure.

It has been apprehended that this might be a restraint on the public, who make use of sun-dials; and the Institute has thought that government in this measure ought to take the lead by causing the clocks in the national buildings to be regulated by mean time. I do not despair of seeing adopted this new kind of exactness, which is necessary on account of the present improved state of the arts and the sciences. M. Henry Lepaute, on the 26th of December, erected in the Institute a beautiful clock, which will serve as a regulator; it indicates both mean and true time.

The astronomy of the planets has this year made some progress. M. Delambre has reconstructed tables of the sun, by introducing fourteen new equations furnished him by the theory of Laplace', and calculating 500 observations of Bradley and Maskelyne. He has increased the mass of Venus, which he employed in 1792 , in the ratio of 92 to 104 , and diminished that of Mars in the ratio of 100 to 72 .

The tables of the moon of M. Burg have been correctcd by introtucing new positions of the stars, and the equation of 180 years, found by Laplace. M, Burg has found the longitude of the moon for 1801 to be $3^{s} 15^{\circ} 1^{\prime} 17 \cdot 3^{\prime \prime}+$ $10^{\circ} 2^{\prime \prime}+0 \cdot 8^{\prime \prime}$, and the secular motion $10^{5} 7^{\circ} 52^{\prime} 43 \cdot 5^{\prime \prime}$.

On the 1st of November M. Burckhardt presented the result of his calculations, in which he found $4 \cdot 6^{\prime \prime}$ less than the longitude given by M. Burg, whose tables come down only to the 17 ih of November.

L. and anom. $1801-3^{\mathrm{s}} 15^{\circ} 1^{\prime} 12 \cdot 7^{\prime \prime} \mid 0^{\mathrm{s}} 18^{\circ} 56^{\prime} 55 \cdot 6^{\prime \prime}$ Secular mot. - - - $10 \quad 7 \quad 52 \quad 45 \cdot 5 \mid \begin{array}{llllll}6 & 18 & 49 & 17 \cdot 8\end{array}$

The difference arises from the new equation of M. Laplace, which M. Burg, perhaps, made too small.

The eclipse of the sun which took place on the 16 th of 
August was observed almost every where; it furnished us with the verification of several longitudes, and gave us a rigorous agreement in the tables.

M. Burg, who refused ti) come to France with an advantageous appointment, has been indemnified by a pension from the emperor.

M. Leupold, who was cmployed with me in observations and calculations, made preparations for observing the eclipse at Bourdeaux with M. Lescan, professor of hydrography; M. Ducom, professor of navigation; and M. Thibaut, a captain in the navy: but the weather was not favourable.

I have nade new tables of Mercury and Venus, by employing the perturbations or inequalities produced by the attraction of the other plancts. M. de Laplace had given the equations estimated by M. Bouvard.

M. Burckhardt calculated the tables. I corrected the elements according to the latest observations, and I have had the satisfaction to see that the new ones are so exact that no errors of any consequence can be found in the most correct observations of Mercury and Venus.

M. Flaugnergues has calculated the equation of Mercury in tenths and seconds, and the logarithms to eight places.

The following is the last inferior conjunction of Vents, observed at Paris by Burckhardt and Lalande my nephew :

Mcan time of the true conjunction December $31 \mathrm{st}, 3^{\text {h }}$ $15^{\prime} 3^{\prime \prime}$; and the true longitude, counted from the mean equinox, $9^{\text {s }} 9^{\circ} 19^{\prime} 5^{\prime \prime}$.

It gives for the correction of the present tables, $-13^{\prime \prime}$ in longitude, and $-1^{\prime \prime}$ in latitude; but by means of the correction which $I$ made in the epochs and mean motions there remains only $1^{\prime \prime}$ of error for the longitude. I find in $1795,1^{\prime \prime}$; in $1796,9^{\prime \prime}$; in $1798,1^{\prime \prime}$; in $1799,1^{\prime \prime}$; in 1801 , zero: which proves that there is no change to be made in the new elements.

In the digression of March 13, 1803, M. Flauguergues found $+21^{\prime \prime}$ and $+4^{\prime \prime}$.

In the month of May 1804 Venus will astonish the public by her great splendour; and we shall be obliged to announce in our journals, that she is not a new star, nor an extraordinary comet.

The opposition of Mars at the end of $1802-6^{\prime \prime}$ in longitude, $+z^{\prime \prime}$ in latitude, for the tables which Lalande my nepher published in the Connoissance des Temps for the year 12,1804 .

M. Bouvard has reconstructed the tables of Jupiter according to observations made for ten years, employing

$$
\mathrm{O}_{4}
$$


equations of conditions which give the means of verifying all the elements. He has brought them to such perfection that the errors amount only to $10^{\prime \prime}$; but the mass of Saturn, reduced to $55^{3} 16$, is more exact than that deduced from the satellites,

The opposition of Jupiter gives $-\mathcal{Q}^{\prime \prime}$ in longitude.

The opposition of Saturn in the month of March gave for the correction of the tables in longitude $-17^{\prime \prime}$, and in latitude zero. But M. Bouvard will undertake the same labour in regard to Saturn as that which be has announced on Jupiter.

The disappearance of Saturn's ring, according to the calculations of Dusejour, will not take place till the end of June.

For the end of December he found only an almost disappearance, or an instantaneous disappearance $*$; a tendency to disappear + . But the disappearance was complete from the 2oth of December to the 10th of January, according to M. Mechain and M. Flauguergues, at Viviers. I have thence deduced the place of the node of Saturn's ring in the ecliptic $5^{\mathrm{s}} 17^{\circ} 11^{\prime}$; the observations of 1774 gave $5^{\mathrm{s}} 17^{\circ}$ $29^{\prime}$ : the difference is small, and makes only $18^{\prime}$ in twentynine years for the motion of the node of the ring. 1 found still less for the anterior disappearances $\downarrow$.

The reappearance took place on the 14 th of June, according to $M$. Flauguergues.

On the 16 th, according to $M$. Vidal; and the result was nearly the same,

Among the rare observations which $M$. Vidal has sent us, there is one very extraordinary. On the 11 th of October he observed Jupiter and Venus at the same time as the limb of the sun: they differed only $10^{\prime}$ in declination: he saw them together in the field of the telescope. He ob. served Saturn in the meridian $20^{\prime}$ before the sun.

Olbers's planet, discovered on the 28th of March 1802, has this year afforded occupation to all the astronomers. It had been lost since the 16 th of October 1802 ; we were all impatient to see it again: M. Harding, of Lilienthal, first enjoyed this satisfaction; on the 19 th of February he saw it like a star of the twelfth magnitude.

M. Messier followed it till the month of September, notwithstanding the extreme difficulty of seeing it with the best telescopes.

Messrs. Burckhardt and Lalande my nephew observed

*Vol. ii. p. 124. + Paye 155. $\$$ Astron. art. 3355. 
it at the Military School, or Maison du Champ de Mars, as long as it could be seen on the meridian. 'They found the opposition on the 29th of June 1803 at $23^{\text {h }} 57^{\prime} 10^{\prime \prime}$ mean time in $9^{5} 7^{\circ} 39^{\prime}$, with $46^{\circ} 26^{\prime} 36^{\prime \prime}$ of latitude.

On the 11 th of July M. Burckhardt gave us the new elements, by which we can find it again in the month of March next.

The sidereal revolution, 1681 days $\frac{8}{10}$; tropical revolution $1680^{\circ} 97$, or 4 years 7 months 11 days.

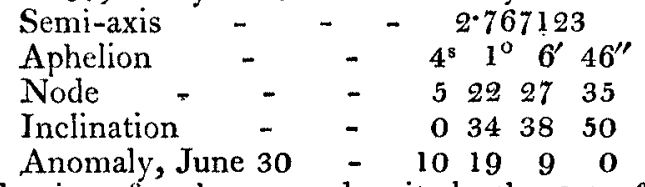

Which gives for the mean longitude the lst of January $1804,9^{\mathrm{s}} 29^{\circ} 52^{\prime} 58^{\prime \prime}$; eccentricity the same as in the preceding elements, $0^{\circ} 2463$; diurnal motion, $12^{\prime} 50.983^{\prime \prime}$; annual motion, $78^{\circ} \cdot 10^{\prime} 9^{\prime \prime}$.

M. Burckhardt has been employed in calculating the perturbations experienced by the planets of Piazzi and Olbers. In consequence of the attraction of Jupiter these calculations are exceedingly complex, because the higher powers of the eccentricity and inclination produce a great number of terms.

He has given formulæ of the perturbations to the 5 th power; and he even believes that the eleventh power might furnish sensible terms for that of Olbers. He is engaged in these researches.

On the 18th of Thermidor of the year $1 \mathrm{l}$, according to the senatus consultum of the 26th of Vendemiaire preceding, government admitted M. Burckhardt to the privileges of a French citizen, Want of this admission prevented him from being a member of the Institute at the last election. Government wished to indemnify him by a flattering distinction due to exalted merit. This is a new encouragement to the labours with which he daily enriches astronomy.

On the 4th of April the Institute decreed, for the first time, the prize of astronomy which I founded the preceding year. It was adjudged to Dr. Olbers for his discovery of a tenth planet.

I see with regret, that the Germans have no more respect for Dr. Olbers than they have for Dr. Herschel. The name of Pallas has no foundation: jealousy, perhaps, is the cause of this injustice.

I have had the satisfaction to find that astronomy is extending 
tending even in America. Don Antonio de Robredo bas sent me from the Havannah minute calculations of the eclipse of the sun, on the 10th of February 1804, made by the analytical methods of $M$. Dusejour, for every country of the earth, with all the dimensions of the curves of illumination. These calculations, more extensive and more exact than those in the Connoissance des Temps for the year 12, arrived too late to be inserted in that work; which I much regretted.

The French government has resolved to re-establish the mission to China, which is equally useful to the scicnces and to political relations. One of our ablest astronomers has formed the project of going thither; and however great his utility may be here, I did not oppose this plan of going to a distance from us, in order that he may still be of more service to us.

The duke of Brunswick has resolved to cause an observatory to be constructed. Baron von Zach has been at Brunswick for that purpose; and I have thanked, in the name of all astronomers, the prince who increases the number of heroes, protectors of astronomy, whom I have mentioned in the preface to my work on that subject.

The Italian republic has requested arı astronomer to cooperate with M. Ciccolini in the observations made in the Institute of Bologna.

M. Vassalli-Eandi has requested that the observatory of Turin may be put into a state of activity.

The margrave of Baden, having taken possession of Manheim on the 23d of November $180 \%$, preserved the instruments of the observatory; and M. Bary has announced to me a new series of observations.

My Billiographie Astronomique appeared on the 5 th of June in a quarto volume of 900 pages. It contains as large a catalogue, as I was able to make, in the course of thirty years, of all the astronomers and all the works on astronomy which have appeared for two thousand years.

Bailly"s large History of Astronomy terminated at 1781: I have continued it to the end of $180 \%$.

M. Goudin has given a new edition of his Astronomical Memoirs.

On the 17 th of March the Board of Longitude published the Connoissance des Temps for the year 13, which contains every thing relating to astronomy that has been done in the countries where it is cultivated: the history and observations of the new planets and of the last comets; a new catalogue, which makes the number of the stars known to be 
13,000; memoirs and observations by baron von Zach and M. Ciccolini, Delambre, Mechain, Vidal, Flauguergues, Goudin, Sorlin, Lalande uncle and nephew, Burckhardt, Nouet, Chabrol de Murol, and Thulis; with the History of Astronomy for the years 8 and 9 , to serve as a continuation of that given for the preceding years since 1782 .

The Connoissance des Temps for the year 14 is on the point of appearing: it contains all the calculations of the moon made from our new tables for the use of the navy, with a great number of observations, tables, and memoirs, by Laplace, Delambre, Vidal, Herschel, Messier, Burckhardt, Lalande uncle and neplew, Olbers, Thulis, Flauguergues, and Duc-la-Chapelle; the history of astronomy for 1802 ; supplements to ny Billiographie; tables of aberration for 140 stars, a twelfth catalogue of new stars, a table of the changes in longitude and latitude for 600 principal stars, the measurement of the degree in Lapland, and a table of all the articles contained in the forty-five last volumes of the Connoissance des Temps since 1760 , when I began to keep a register of the annual progress of astronomy.

M. Legendre has given to the Institute a new formula for the reduction of the apparent distances, with tables for simplifying the use of them : there are already a great number: we shall have an opportunity of choosing that which appears the easiest and shortest.

M. de Laplace has given in the Bulletin a theory of the deviation of falling bodies, in consequence of the experiments of $\mathrm{M}$. Guglielmini and Henzenberg. The result is, that the deviation ought to be null towards the south, though M. Guglielmini found it to be three lines. But these experiments are so difficult to be made, and the resistance of the air so little known, that this does not impeach the results of M. Guglielmini.

The Ephemerides of Milan for 1802 contain observations of-Mercury; of the occultation of the Spica Virginis on the 30th of March 1801; tables of the annual parallax of Mars, of the precession of the stars, and of the motion peculiar to a great number of them.

Those of 1803 contain the perturbations of Piazzi's planet by $M$. Oriani, and observations of that planet and of that of Olbers.

M. Laurent Regnier, professor of astronomy at Upsal, has published a dissertation De Massis Cometurum.

The Ephemerides of Vienna for 1804 contain observations of different places by $M$. Triesnccker and M. Burg. 
The latter gives a series of observations of the moon, which may serve to verify his tables.

On the 24th of September 1803 we received the tenth volume of the Transactions of the Italian Society, which contains a valuable catalogue of the stars by M. Cagnoli; the opposition of Herschel in 1794 by Slop and oppositions of Mars by Chiminelli, at Padua, in 1790, 1792 , and 1794.

The Society of the Sciences at Warsaw has published a volume of memoirs, in which there are observations by M. Sniadecki.

On the 24th of October 1803 we received the Memoirs of the Acadeiny of Sciences at Berlin for 1799 and 1800 , in which there are anecdotes for the History of the Mathematics by Bernoulli; the pendulum which swings seconds at Berlin, by M. Burja, 3 f. 2 in. 0.24 lines; a memoir on the problem of the precession of the equinoxes, by the formulæ of Lagrange, by M. John Trembley; and astronomical observations $1798-1800$ by $M$. Bode.

My small sterentype tables of logarithms, the most exact, most convenient, and cheapest ever published, have been again collated by M. Bubna : no faults were found in them; and $I$ announced that $I$ would give a hundred francs for each fault which might be discovered.

Besides the interesting journal of baron Von Zach, entitled Monatliche Correspondenz der Erde und Himmelkunde, there is one at Weimar entitled Algemeine Geographische Ephemeriden, by Gaspari and Bertuch : the number for February 1803 contains an engraving of the celebrated astronomer Joseph Nicholas de lisle, from a painting at Paris in the possession of Messier.

We have received the Memoirs of the Academy of Pctersburgh for 1795 and 1796, in which there are observations of Henry; memoirs by Schubert on the theory of the moon and on the transits of Mercury; one by M. Rumouski on the figure of the earth; two by M. Kraft on nautical astronomy; and one by M. Inochodzof on the heights of several places observed by the barometer.

M. Novoziltzoff, president of the academy, has caused to. be placed in the observatory a beautiful transit instrument, which he purchased from Rumsden during his residence at London. On the 25 th of July he obtained an increasc of the funds of the acadeny.

M. Wisniewski, of Warsaw, has been invited to Petersburgh on the recommendation of professor Bode, whom he assisted. He arrived there on the 1 st of August, and began 
his labours in the observatory with great zeal. The president expects to draw to Petersburgh an astronomer of reputation.

Hitherto we have seen no native of Russia distinguish himself in that country by astronomy. But I experienced an agreeable surprise, and entertain consoling hopes, when I see young Alexander Oulibisheff, at the age of ten, converse with me on astronomy in a manner 1 never before witnessed, even in France, from persons of twenty years of age. He was born at Moscơw on the 27 th of November 1793.

The emperor of Russia, in the new statutes of the imperial university of Vilna, issued on the sth of May, ordered that there shall be an observer and professor of astronomy. M. Poczobut, who has long resided there, is a pledge that our science will not be neglected.

M. Sniadecki, a Polish astronomer, formerly of Cracow, not having been able to obtain from the Austrian government the necessary assistance for that observatory, has preferred the observatory of Vilna, where he will assist M. Poczobut.

M. Honoré Ponz, an ingenious clockmaker, whose excellent clocks I have announced, has this year made an important improvement by adding free escapements, which are ingenious, and which by means of remontoirs leave no room for the inequalities of rouage to affect the motion of the pendulum. He presented a description of it to the Institute on the 19th of December.

[To be continued.]

$\longrightarrow$

XXXVIII. A Letter to Governor Pownall from Dr. ThorNTON.

April 16, 1804 , No. r, Hinde-street, SIR, Manchester-square.

I was pleased to find a gentleman of your sound judgment, matured by the enjoyment of long life, chiefly consecrated to science, observing the changes of men and things, recalling the philosophic world to the sentiments entertained by our forefathers. When Dr. Priestley made his discoveries in chemistry, like John Hunter he disclaimed all the advantages of reading; and the French chemists, catching at the seemingly. new lights he threw out, formed a brilliant system which went to acknowledge no authori- 